\title{
A Statistical Approach to Analyze the Factors Affecting Family Planning in Bangladesh
}

\author{
Ataul Mustufa Anik, Shabab Noor Islam, Shahber Hassan, Susmoy Saha, Nayema Taskin Nabila \\ Department of Statistics, Shahjalal University of Science \& Technology, Sylhet, Bangladesh \\ Email: am08anik@gmail.com
}

How to cite this paper: Anik, A.M., Islam, S.N., Hassan, S., Saha, S. and Nabila, N.T. (2019) A Statistical Approach to Analyze the Factors Affecting Family Planning in Bangladesh. Open Journal of Statistics, 9, 74-84.

https://doi.org/10.4236/ojs.2019.91007

Received: October 22, 2018

Accepted: January 27, 2019

Published: January 30, 2019

Copyright $\odot 2019$ by author(s) and Scientific Research Publishing Inc. This work is licensed under the Creative Commons Attribution International License (CC BY 4.0).

http://creativecommons.org/licenses/by/4.0/

\begin{abstract}
Family planning is one of the essential tools for reducing maternal and neonatal mortality rate. Several potential factors influence the usage of contraception, and the purpose of the paper is to identify the relevant ones among them. Using the data of BDHS 2014, cross tabulation and the multinomial logistic regression model is used to analyze the association of different factors. The 2014 BDHS gathered data from more than 17,000 families and more than 17,800 married women. There are many factors that can be associated with the application of family planning but among them. Heard about family planning on Newspaper/magazine, Time spending on Television, heard about family planning from media such as Television, Radio, etc., Household has: Radio appeared as the significant determinants of family planning. In this research, it is found that $94.9 \%$ did not use family planning where else only $5.1 \%$ used family planning. Among those who used family planning methods $32.6 \%$ used pills, $16.1 \%$ used injections, $7.2 \%$ used condoms, $3.2 \%$ used female sterilization, $0.6 \%$ used male sterilization, etc. Arranging various campaigns and use of mass media is fundamental to raise awareness about family planning.
\end{abstract}

\section{Keywords}

Family Planning Practice, Factors, Contraceptive Prevalence Rate, Bangladesh

\section{Introduction}

Family planning is broadly known for controlling the number of child in a family and amid the births. Family planning (FP) has been recognized by the World Health Organization (WHO) as one of the basic conceptive wellbeing intercessions expected to accomplish safe parenthood by diminishing maternal and child mortality [1]. It can avert unfortunate pregnancies and dangerous premature 
births. Family planning techniques keep individuals from STI (Sexually Transmitted Infections) [2] [3] [4]. It has been discovered that sex fairness and also educational and monetary strengthening are advanced by family planning [5]. Family planning may include the thought of the number of children a woman wishes to have, including the decision to have no children, and the age at which she wishes to have them. These cases are impacted by outer factors, for example, marital circumstance, profession contemplations, monetary position, any inabilities that may influence their capability to have children and raise them. Other than these components, it has additionally been watched that the attention to the accessibility of family planning services impacts the take-up of family planning methods [6].

There are different sorts of family planning methods, for instances, Birth Control Implant, Birth Control Patch, Birth Control Pill, Birth Control Shot, Birth Control Sponge, Birth Control Vaginal Ring, Cervical Cap, Condom, Diaphragm, Female Condom, Fertility Awareness Methods (FAMs), Intrauterine Device (IUD), Outercourse and Abstinence, Spermicide, Sterilization (Tubal Ligation), Vasectomy, Withdrawal (Pull Out Method). As indicated by the WHO, family planning enables people and couples to anticipate and accomplish their wanted number of children and the balance and timing of their births. It is accomplished through the utilization of contraceptive techniques and the treatment of automatic fruitlessness [7].

The awareness for the use of conceptive is on the increase worldwide, consequently a reduction in maternal death rate. Ordinarily, contraceptive prevalence is higher in nations where there are more noteworthy access and accessibility of contraceptive techniques [8]. Regardless of the current worldwide augmentation in the prevalence of modern contraceptive use, many developing and underdeveloped countries are as yet experiencing the outcomes of high neglected requirements for present-day contraceptives [9]. Projects and policy intended to decrease the inadmissibly high levels of unintended pregnancy in the United States could be enhanced by a superior comprehension of why some women experience issues utilizing contraceptives consistently even when they would prefer not to end up pregnant. An assortment of studies has concentrated on individual factors or nature of factors, affirming the relationship between contraceptive behavior and key attributes of women. However few have thought about numerous sorts of factors at the same time. For instance, women of low financial status commonly have brought down rates of contraceptive use and higher rates of contraceptive disappointment and unintended pregnancy than women of higher financial status [10] [11] [12]. In developing countries and especially African nations, it is vital to consider that the state of mind towards and use of contraception may change because of a large number of factors, including the nature of the health administration and its experts, accessibility of and access to family planning methods [13], level of revenue [14], sexual aspect and the financial background of the country [15]. There is further a doubt of various outside suppliers, and the contraception pills may be erroneously observed as a type of 
sterility drugs. A couple of different barriers are the young marital ages, the absence of women's empowerment and the high sex imbalance [16]. In the Middle East, information and use of contraception are predominant in fluctuating degrees and have been appeared to negatively affect fertility. Likewise, contraceptive use and postponed marriage have been appeared to effectively affect fertility reduction [17]. An investigation on the countries of the Middle East found that in some culture, women wedded at young ages, and women with a more noteworthy number of children wanted bigger families; while women's training and spouse's education negatively affected on fertility desire. Women with higher education, women whose companions were more educated, and women who had come to or surpassed their optimal family measure will probably utilize contraception [18]. In South Asia, different nations have made family planning a first concern, especially Bangladesh, Nepal, India, Pakistan, and Sri Lanka. In these nations, recognizing the determinants of Contraceptive use is unpredictable because the choice to use a contraceptive is impacted by an extensive variety of issues including mental, social and social elements [19]. Most research on the determinants of contraceptive use uncovers that demographic and financial variables are solid indicators of contraceptive use. Among demographic factors women's age, a number of living children, age at first marriage apply solid impact on their choice to utilize contraceptives [20] [21]. Then again, financial components, for example, education, service status, monetary status, and place of living decide the extent to which women can take the choice of contraceptive utilize and use those [22] [23] [24]. With couple of exemptions, the discoveries of the past research recommend that women with lower financial status are more reluctant to utilize contraceptives because of their absence of knowledge about sources and techniques for preventative, absence of awareness about negative outcomes of having more children on their wellbeing and career, lower role in basic leadership in regards to utilizing contraceptives, and absence of ability to buy current contraceptives [25] [26]. Concerning the part of media presentation, there is prove that women who approach daily paper, radio and TV will probably utilize contraceptives [23] [27]. In some researches, it's also found that month to month family wage and number of living children were essentially connected with the utilization of current contraceptives. Want for more children, spouse's endorsement and couple's discourse about family planning issues applied the solid effect on the choice to utilize modern contraceptives [21]. Expanding landlessness, underemployment in the rural areas is the major factors to cause a constant shift of the rural poor to the urban sector [28] [29]. The contraceptive use of the urban poor is even getting worse than that of the rural poor [30]. Therefore, the study is conducted to explore the factors which are responsible for taking family planning methods and to analyze the demographical status of family planning in the rural and urban area.

\section{Methodology}

The investigation utilizes information from the Bangladesh Demographic and 
Health Survey (BDHS 2014), which was directed as a major aspect of the worldwide Demographic and Health Survey (DHS) under the acquiescence of the National Institute for Population Research and Training of the Ministry of Health and Family Welfare with the monetary help of the US Agency for International Development. The National Institute of Population Research and Training (NIPORT) of the Ministry of Health and Family Welfare (MOHFW) conducted the 2014 Bangladesh Demographic and Health Survey (2014 BDHS). The sample for the 2014 BDHS is broadly illustrative compared with later surveys and covers the whole populace dwelling in non-institutional abiding units in the nation. The overview utilized an inspecting outline from the rundown of enumeration areas (EAs) of the 2011 Population and Housing Census of the People's Republic of Bangladesh, gave by the Bangladesh Bureau of Statistics (BBS). Around 120 family units within an EA were made to be the primary sampling unit (PSU). Bangladesh is partitioned into seven managerial divisions: Barisal, Chittagong, Dhaka, Khulna, Rajshahi, Rangpur, and Sylhet. Every division is partitioned into Zila's and each Zila into Upazilas. Each urban territory in an Upazilais separated into wards, which are additionally subdivided into mohallas. A rustic zone in an Upazila is partitioned into union parishads (UPs) and, inside UPs, into mouzas. These divisions permit the nation, all in all, to be divided into rural and urban zones. Intended to give national and divisional information on virility, family planning, child mortality, child wellbeing, maternal wellbeing, nourishment of children and women, HIV, and women empowerment, the 2014 BDHS gathered data from over 17,000 families and more than 17,800 married women. The overview comes about give data to assess existing wellbeing and social projects and to plan new methodologies for enhancing the health status of the nation's women and children.

\section{Data Analysis}

In the analysis, we have performed both descriptive and analytical statistics. We have done the descriptive analysis to see the demographic status, cross-sectional study, and multinomial logistic regression analysis to see the dependency of any factors associated with family planning. Chi-square test also has performed to justify the hypothesis.

\section{Results}

In our study, from Multinomial logistic regression we can see that, for family planning Heard about family planning on radio last few months, the Wald test statistic is 11.430 with an associated p-value 0.001. If we set our alpha level 0.05 , we would not accept the null hypothesis and conclude that for family planning relative to Heard about family planning on radio last few months has been found to be statistically significant in the model. The odds ratio of the Heard about family planning on radio last few months is 6.285 that is a person who has no radio is 6.285 times likely not to take family planning than a person who has a radio. Here our reference category is yes, which is described in Table 1. 
Table 1. Parameter estimates.

\begin{tabular}{|c|c|c|c|c|c|c|}
\hline \multirow[t]{2}{*}{ Currently using Family Planning } & \multirow{2}{*}{$\begin{array}{l}\text { Std. } \\
\text { Error }\end{array}$} & \multirow[t]{2}{*}{ Wald } & \multirow[t]{2}{*}{ Sig. } & \multirow{2}{*}{$\begin{array}{l}\text { Exp } \\
(B)\end{array}$} & \multicolumn{2}{|c|}{$\begin{array}{l}95 \% \text { Confidence } \\
\text { Interval for } \operatorname{Exp}(B)\end{array}$} \\
\hline & & & & & Lower Bound & Upper Bound \\
\hline Intercept & 0.933 & 0.057 & 0.812 & & & \\
\hline Heard about family planning on radio last few months & 0.544 & 11.430 & 0.001 & 6.285 & 2.165 & 18.245 \\
\hline Heard about family planning on TV last few months & 0.240 & 37.933 & 0.000 & 4.390 & 2.742 & 7.029 \\
\hline Heard about family planning in newspaper/magazine last few months & 0.338 & 10.846 & 0.001 & 3.041 & 1.569 & 5.895 \\
\hline Got Service from community clinic: family planning method & 0.744 & 2.552 & 0.110 & 0.305 & 0.071 & 1.310 \\
\hline Heard about family planning method from community health worker & 0.251 & 5.630 & 0.018 & 1.816 & 1.109 & 2.972 \\
\hline Literacy & 0.397 & 0.452 & 0.501 & 1.306 & 0.600 & 2.840 \\
\hline Frequency of reading newspaper or magazine & 0.237 & 8.834 & 0.003 & 2.025 & 1.272 & 3.224 \\
\hline Frequency of listening to radio & 0.505 & 2.101 & 0.147 & 0.481 & 0.179 & 1.294 \\
\hline Frequency of watching television & 0.309 & 7.158 & 0.007 & 2.286 & 1.247 & 4.190 \\
\hline
\end{tabular}

a. The reference category is: Yes; $b$. This parameter is set to zero because it is redundant.

From family planning relative to Heard about family planning on TV last few months the Wald test statistic is 37.933 with an associated p-value 0.000 . At 5 percent level of significance, we would not accept the null hypothesis and concludes that family planning relative to Heard about family planning on TV last few months are statistically significant. The odds ratio for the Heard about family planning on TV last few months with respect to family planning is 4.390 means that people who don't have a TV are 4.390 times more likely not to take family planning than who has a TV in their household. It is a common factor since watching TV we can learn a lot about the advantages and disadvantages of family planning.

Family planning relative to Heard about family planning in newspaper/magazine last few months the Wald test statistic is 10.846 with an associated p-value 0.001. At 5 percent level of significance, we would not accept the null hypothesis and concludes that family planning relative to Heard about family planning in newspaper/magazine last few months are statistically significant. The odds ratio for the Heard family planning in newspaper/magazine last few months with respect to family planning is 3.041 means that people who don't read newspaper/magazine are 3.041 times more likely not to take family planning than who read newspaper/magazine. Family planning with respect to Service from community clinic: family planning method the Wald statistic is 2.552 with p-value 0.110. At 5 percent level of significance, we would fail to reject the null hypothesis and conclude that Service from community clinic: family planning method and family planning are statistically different.

Again family planning with respect to Heard of family planning method from community health worker the Wald statistics is 5.630. At 5 percent level of significance, we would not accept the null hypothesis and concludes that family plan- 
ning relative to Heard of family planning method from community health worker is statistically significant. It is usual as family workers play a significant role in the use of family planning. They can make awareness among people to take family planning also can help people about the pros and cons of family planning.

Family planning with respect to literacy, the Wald statistic is 0.452 with p-value 0.501 . At 5 percent level of significance, we would fail to reject the null hypothesis and conclude that literacy and family planning are statistically different.

The frequency of reading newspaper or magazine relative to family planning the Wald test statistic is 8.834 with an associated p-value 0.003 . At 5 percent level of significance, we would not accept the null hypothesis and concludes that family planning relative to Frequency of reading newspaper or magazine is statistically significant. It implies that if a person read newspaper or magazine, they are more likely to take family planning then who don't read a newspaper/magazine frequently.

The frequency of watching television relative to family planning the Wald test statistic is 7.158 with an associated p-value 0.007. At 5 percent level of significance, we would not accept the null hypothesis and concludes that family planning relative to Frequency of watching television is statistically significant. It implies that if a person watches television frequently, they are more likely to take family planning then who don't watch television frequently.

Moreover, we have tried to discover which methods are more preferable in family planning. There are various methods used by different peoples. From the analysis, we can see that $32.3 \%$ of people are currently not using any methods. $32.6 \%$ people use Pill which is the highest using method in family planning. IUD is used by $0.6 \%$ of people. Injections are used by $16.1 \%$ of people. While Condom is used by only $7.2 \%$ people, it is quite surprising as it is the safest way, but men in Bangladesh preferred it less as the study shows. There are also other methods like Female sterilization, Male sterilization, etc. which is shown in the graph (Figure 1).

We also run a crosstab analysis amongst the associated factors, which are tabulated below (Table 2).

It is quite astonishing that the majority of part $99.4 \%$ of people had not been using family planning since they have no source.

Some graph used for showing some other factors and their effects on family planning (Figures 2-4).

From Kamruzzaman et al., it was found that $45.71 \%$ women practiced family planning while $15.71 \%$ due to husband pressure, $11.71 \%$ due to financial problem, $6.28 \%$ participants due to health condition and 54.29\% were not used Family Planning while $18.0 \%$ due to fear of side effect, $12.0 \%$ due to wanting more children and only $1.43 \%$ were for religious beliefs. Regarding to the current practice of family planning, $20 \%$ of the respondents used pills, $10 \%$ injections and $4.29 \%$ condom users [30]. 


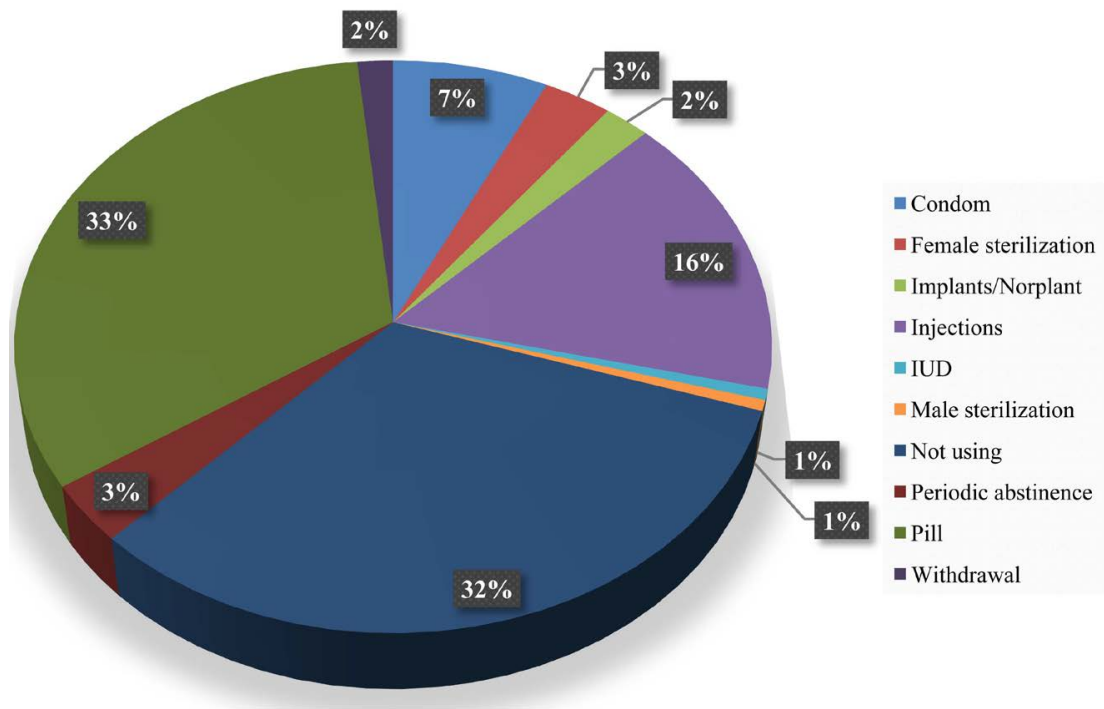

Figure 1. Different contraceptive methods of family planning.

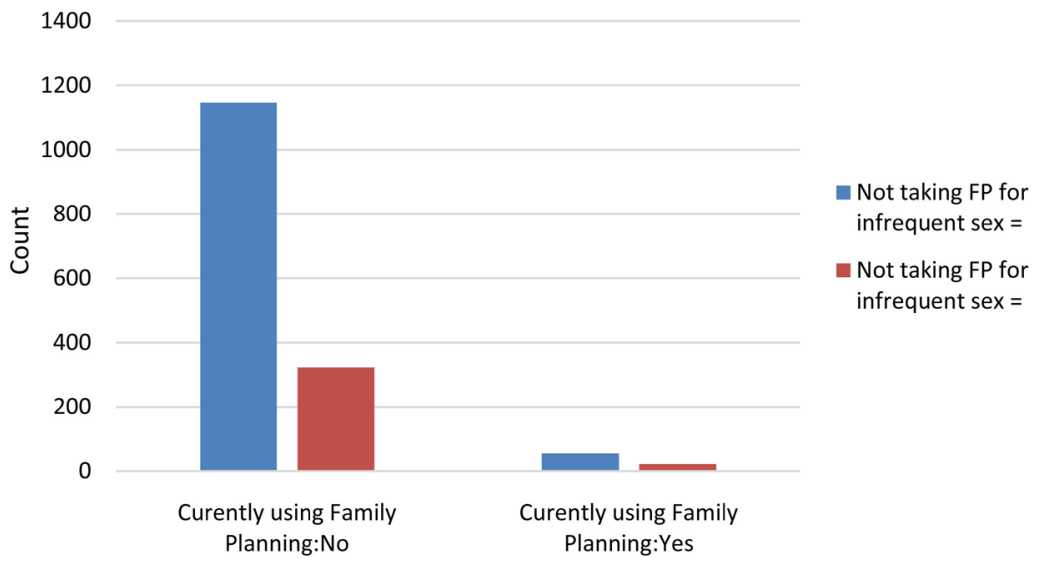

Currently using Family Planning

Figure 2. Clustered bar chart of currently using family planning and not taking FP for infrequent sex.

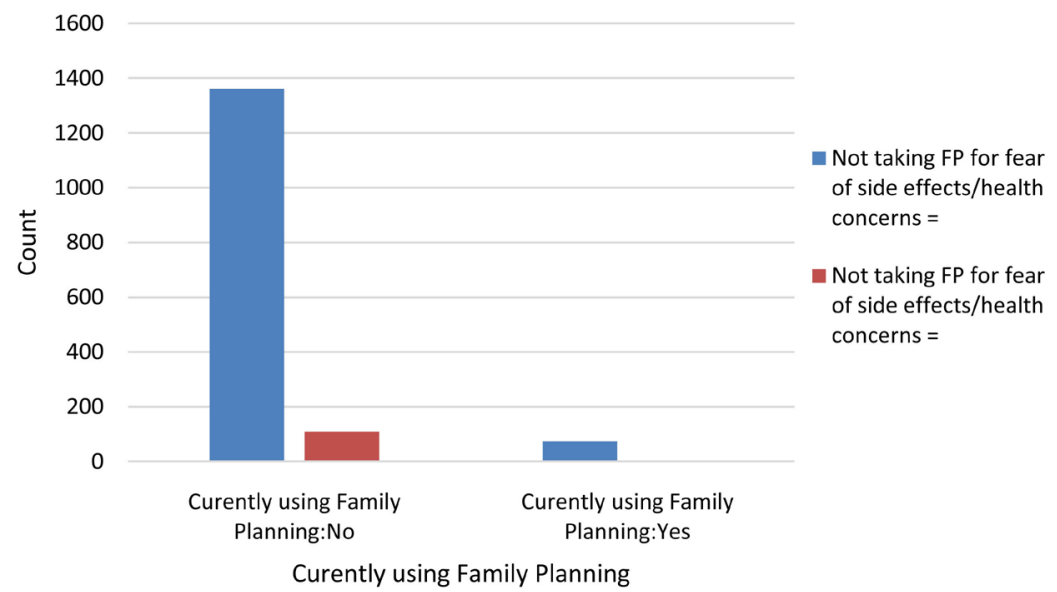

Figure 3. Clustered bar chart of currently using family planning and not taking FP for fear of side effects/health concerns. 


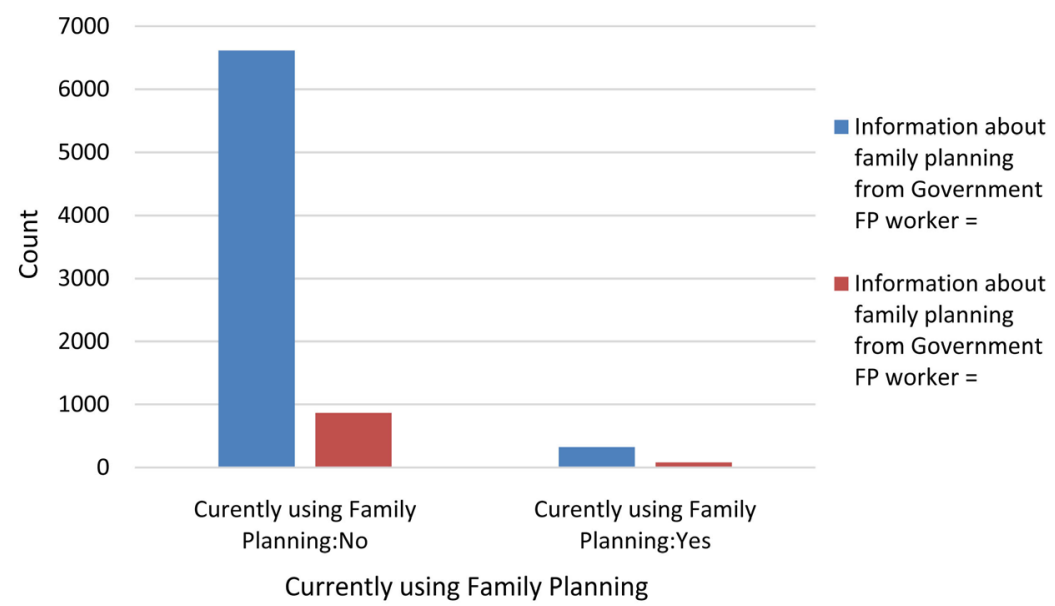

Figure 4. Clustered bar chart of currently using family planning and source of information about family planning: government FP worker.

Table 2. Crosstab analysis amongst the associated factors.

\begin{tabular}{|c|c|c|}
\hline & Factors & Percentage \\
\hline \multirow{3}{*}{$\begin{array}{l}\text { Heard Family Planning in a } \\
\text { poster/billboard last month factor }\end{array}$} & Yes & $94.5 \%$ \\
\hline & No & $5.5 \%$ \\
\hline & Factors & Percentage \\
\hline \multirow{4}{*}{$\begin{array}{l}\text { Visited by Family Planning } \\
\text { worker in the pastsix months }\end{array}$} & People have not talked about planning & $74.7 \%$ \\
\hline & People have talked about family planning & $14.2 \%$ \\
\hline & People took family planning method & $7.5 \%$ \\
\hline & People talked and received family planning & $3.6 \%$ \\
\hline \multirow{2}{*}{ Household have television } & Yes & $51.8 \%$ \\
\hline & No & $48.2 \%$ \\
\hline \multirow{2}{*}{ Household have Radio } & Yes & $89.8 \%$ \\
\hline & No & $11.2 \%$ \\
\hline \multirow{2}{*}{ People's residence } & Urban & $34.1 \%$ \\
\hline & Rural & $65.9 \%$ \\
\hline \multirow{4}{*}{ Education Status } & No education & $15.2 \%$ \\
\hline & Primary & $27.4 \%$ \\
\hline & Secondary & $46.4 \%$ \\
\hline & Higher Secondary & $11 \%$ \\
\hline \multirow{2}{*}{ Terminate pregnancy } & Yes & $16.4 \%$ \\
\hline & No & $83.6 \%$ \\
\hline \multirow{3}{*}{ Using of contraception } & Self-decision & $13.1 \%$ \\
\hline & partner's/husband's decision & $9.5 \%$ \\
\hline & jointly decision & $77.4 \%$ \\
\hline \multirow{5}{*}{$\begin{array}{l}\text { Not taking family } \\
\text { planning (Reasons) }\end{array}$} & Fatalistic & $2.5 \%$ \\
\hline & Not Fatalistic & $97.5 \%$ \\
\hline & Opposition of partner & $96.2 \%$ \\
\hline & Against the opposition of partner (taking) & $3.8 \%$ \\
\hline & Religious prohibition & $98.8 \%$ \\
\hline \multirow{3}{*}{$\begin{array}{l}\text { Taking Family planning } \\
\text { (no source) }\end{array}$} & Against religious prohibition (taking) & $1.2 \%$ \\
\hline & Yes & $0.6 \%$ \\
\hline & No & $99.4 \%$ \\
\hline
\end{tabular}


From Ferdousi Sk, Jabbar Ma, Hoque Sr, et al., it was found that nearly three quarters $(72.1 \%)$ of the respondents was using contraceptives and rest was not using any method. Among the non-user, (5.04\%) of respondent were eager to conceive, $(0.36 \%)$ was sterile and remaining $22.4 \%$ of the respondents, though need family planning methods due to various reasons, were not getting the facilities. Most commonly used contraceptive methods were oral contraceptive pills $61.7 \%$ and condom $21.4 \%$. Nearly half of the respondents $(46.1 \%)$ were not using contraceptives in fear of side effect. Among other reasons were a religious bar, husbands' noncooperation, ignorance about the method, not informed by F. P. worker and economic constraints, etc., here multiple responses were found [31].

Given findings and observations, it is revealed, although achievement of family planning program in Bangladesh is quite satisfactory but still many women are not taking Family planning at their wish for the consciousness of health, religious belief, etc. But the favorable methods of family planning are quite remaining same as those are safe for a health condition and adequately found in almost every area.

\section{Conclusion}

This study has tried to provide evidence for the demonstration that although the awareness of family planning services is high among the community, it does not necessarily increase the uptake of family planning services if community members are not well informed about the benefits of family planning. From our study we have found that factors like Heard about family planning by radio or TV, Newspaper and frequency of watching TV are highly significant with the use of family planning. There also may be other factors that can be associated, but in our study among all the factors, we found these factors as statistically significant. Therefore essential steps should be taken to take family planning or make awareness of family planning in the community-steps such as organizing educational campaigns on the awareness of family planning services by emphasizing on the benefits of the services. It will help to reduce misconceptions and increase access and utilization of family planning services. Furthermore, males should also be educated on the benefits of family planning services to reduce opposition from husbands.

\section{Acknowledgements}

The authors thank the Bangladesh Demographic Health and Survey for providing the data of 2014 and also our gratitude to the volunteers for their contribution.

\section{Conflicts of Interest}

The authors declare no conflict of interests.

\section{References}

[1] United, N. (2005) The Millennium Development Goals Report. New York. 
http://unstats.un.org/unsd/mi/pdf/mdg\%20book.pdf

[2] Eliason, S., Baiden, F., Quansah-Asare, G., Graham-Hayfron, Y., Bonsu, D., Phillips, J. and Awusabo-Asare, K. (2013) Factors Influencing the Intention of Women in Rural Ghana to Adopt Postpartum Family Planning. Reproductive Health, 10, 34. https://doi.org/10.1186/1742-4755-10-34

[3] Cates, W.J., Abdool Karim, Q., El-Sadr, W., Haffner, D.W., Kalema Zikusoka, G., et al. (2010) Global Development. Family Planning and the Millennium Development Goals. Science, 329, 1603. https://doi.org/10.1126/science.1197080

[4] Sachs, J.D. and McArthur, J.W. (2005) The Millennium Project: A Plan for Meeting the Millennium Development Goals. Lancet, 365, 347-353. https://doi.org/10.1016/S0140-6736(05)70201-4

[5] Yue, K., O’Donnel, C. and Sparks, P.L. (2010) The Effect of Spousal Communication on Contraceptive Use in Central Terai, Nepal. Patient Education and Counseling, 81, 402-408. https://doi.org/10.1016/j.pec.2010.07.018

[6] Lauria, L., Donati, S., Spinelli, A., Bonciani, M. and Grandolfo, M.E. (2014) The Effect of Contraceptive Counselling in the Pre and Post-Natal Period on Contraceptive Use at Three Months after Delivery among Italian and Immigrant Women. Annali dell'Istituto Superiore di Sanità, 50, 54-61.

[7] http://www.who.int/topics/family_planning/en/

[8] Mbizvo, M.T. and Phillips, S.J. (2014) Family Planning: Choices and Challenges for Developing Countries. Best Practice \& Research Clinical Obstetrics \& Gynaecology, 28, 931-943. https://doi.org/10.1016/j.bpobgyn.2014.04.014

[9] Jacob Stein, R., Bakamjian, L. and Pile, J.M. (2008) Threatened and Still Greatly Needed Family Planning Programs in Sub-Saharan Africa. The ACQUIRE Project/Engender Health, New York.

[10] Finer, L.B. and Henshaw, S.K. (2006) Disparities in Rates of Unintended Pregnancy in the United States, 1994 and 2001. Perspectives on Sexual and Reproductive Health, 38, 90-96. https://doi.org/10.1363/3809006

[11] Fu, H., et al. (1999) Contraceptive Failure Rates: New Estimates from the $1995 \mathrm{Na}-$ tional Survey of Family Growth. Family Planning Perspectives, 31, 56-63. https://doi.org/10.2307/2991640

[12] Ranjit, N., et al. (2001) Contraceptive Failure in the First Two Years of Use: Differences across Socioeconomic Subgroups. Family Planning Perspectives, 33, 19-27. https://doi.org/10.2307/2673738

[13] Creanga, A.A., Gillespie, D., Karklins, S. and Tsui, A.O. (2011) Low Use of Contraception among Poor Women in Africa: An Equity Issue. Bulletin of the World Health Organization, 89, 258-266. https://doi.org/10.2471/BLT.10.083329

[14] Rahman, M., Haque, S.E., Mostofa, M.G., Tarivonda, L. and Shuaib, M. (2011) Wealth Inequality and Utilization of Reproductive Health Services in the Republic of Vanuatu: Insights from the Multiple Indicator Cluster Survey, 2007. International Journal for Equity in Health, 10, 58. https://doi.org/10.1186/1475-9276-10-58

[15] Davis, J. and Lopez-Carr, D. (2010) The Effect of Migrant Remittances on Population-Environment Dynamics in Migrant Origen Areas: International Migration, Fertility, and Consumption in Highland Guatemala. Population and Environment, 32, 216-237. https://doi.org/10.1007/s11111-010-0128-7

[16] Konje, J.C. and Ladipo, O.A. (1999) Barriers to Uptake and Use of Modern Methods of Contraception in Developing Countries. International Journal of Gynecology \& Obstetrics, 65, 287-294. https://doi.org/10.1016/S0020-7292(99)00052-1 
[17] Tabutin, D., et al. (2005) The Demography of the Arab World and the Middle East from the 1950s to the 2000s. A Survey of Changes and a Statistical Assessment. Population, 60, 505-615.

[18] Shah, N.M., Shah, M.A. and Radovanovic, Z. (1998) Patterns of Desired Fertility and Contraceptive Use in Kuwait. International Family Planning Perspectives, 24, 133-138. https://doi.org/10.2307/3038210

[19] Oddens, B.J. and Lehert, P. (1997) Determinants of Contraceptive Use among Women of Reproductive Age in Great Britain and Germany: Demographic Factors. Journal of Biosocial Science, 29, 415-435. https://doi.org/10.1017/S002193209700415X

[20] Chaurasia, A.R. (2014) Contraceptive Use in India: A Data Mining Approach. International Journal of Population Research, 2014, Article ID: 821436.

[21] Mohammed, A., Woldeyohannes, D., Feleke, A. and Megabiaw, B. (2014) Determinants of Modern Contraceptive Utilization among Married Women of Reproductive Age Group in North Shoa Zone, Amhara Region, Ethiopia. Reproductive Health, 11, 13. http://www.reproductive-health-journal.com/content/11/1/13

[22] Mahmood, N. and Ringheim, K. (1996) Factors Affecting Contraceptive Use in Pakistan. The Pakistan Development Review, 35, 1-22.

https://doi.org/10.30541/v35ilpp.1-22

[23] Mensch, B., Arends-Kunening, M. and Jain, A. (1996) The Impact of the Quality of Family Planning Service on Contraceptive Use in Peru. Studies in Family Planning, 27, 59-75. https://doi.org/10.2307/2138134

[24] Westoff, C.F. (2001) Unmet Need at the End of the Century. DHS Comparative Reports No. 1, Macro International, Calverton.

[25] Sedgh, G. and Hussain, R. (2014) Reasons for Contraceptive Nonuse among Women Having Unmet Need for Contraception in Developing Countries. Studies in Family Planning, 45, 151-169. https://doi.org/10.1111/j.1728-4465.2014.00382.x

[26] Mumah, J.N., Machiyama, K., Mutua, M., Kabiru, C.W. and Cleland, J. (2015) Contraceptive Adoption, Discontinuation, and Switching among Postpartum Women in Nairobi's Urban Slums. Studies in Family Planning, 46, 369-386. https://doi.org/10.1111/j.1728-4465.2015.00038.x

[27] Rabbi, A.M.F. (2012) Mass Media Exposure and Its Impact on Fertility: Current Scenario of Bangladesh. Journal of Scientific Research, 4, 383-395.

[28] Stalker, P. (1995) A Fork in the Path: Human Development Choice for Bangladesh. FAO, ILO, UNDP, UNFPA, WHO, The World Bank, Dhaka.

[29] Barkat, A., Howlader, S.R., Khuda, B., Ross, J.A. and Bose, M.L. (1997) Family Planning Unmet Need in Bangladesh: Shaping of a Client-Oriented Strategy. University Research Corporation, Dhaka.

[30] Kamruzzaman, Md. and Abdul Hakim, Md. (2015) Family Planning Practice among Married Women Attending Primary Health Care Centers in Bangladesh. International Journal of Bioinformatics and Biomedical Engineering, 1, 251-255. http://files.aiscience.org/journal/article/pdf/70070091.pdf

[31] Ferdousi, S.K., Jabbar, M.A., Hoque, S.R., Karim, S.R., Mahmood, A.R., Ara, R. and Khan, N.R. (2010) Unmet Need of Family Planning among Rural Women in Bangladesh. Journal of Dhaka Medical College, 19, 11-15. 